\title{
Sustainable education: altering the opinions on renewable energy sources
}

\author{
Inna Č́ábelková ${ }^{*}$, Viktor Blaginin ${ }^{2}$, Wadim Strielkowski ${ }^{3,4}$, and Alexandr Platitsyn ${ }^{5}$ \\ ${ }^{1}$ Department of Trade and Finance, Faculty of Economics and Management, Czech University of Life \\ Sciences Prague, Kamýcká 129, Prague 6, Prague, 16500 Czech Republic \\ ${ }^{2}$ Laboratory of Scientometrics, Ural State University of Economics, 8 Marta str., 62/45, 620144 \\ Yekaterinburg, Russian Federation \\ ${ }^{3}$ Centre for Energy Studies, Prague Business School, Werichova str. 1145/29, 15200 Prague, Czech \\ Republic \\ ${ }^{4}$ Centre for Energy Studies, Cambridge Institute for Advanced Studies, CB1 1AH, King str. 23, \\ Cambridge, United Kingdom \\ ${ }^{5}$ Togliatti State University, Belorusskaya str. 14, 445020 Togliatti, Russian Federation
}

\begin{abstract}
Our paper studies the link between the education and the people's opinions and views of the renewable energy sources (RES). We employ the representative data (1026 respondents) from the Czech Republic. Our empirical model did not reveal any associations between the subjective opinion on the respondents about the possibility to replace electricity generation from conventional sources (such as coal-fired or gasfired power plants, nuclear power plants or large hydroelectric power plants) with the electricity from wind, solar radiation and biomass combustion. In addition, there seemed to be no correlation between the usage of renewable energy in the Czech Republic and the education of the respondents. However, there are strong significant association between the level of education of the respondents and the existence of opinions on the RES. Higher education means higher probability of the existence of such an opinion. Almost one third of the respondents with primary education did not have an opinion on the topic. This might be caused by an increasing interest in RES of people with higher level of education as they are likely to be more open to all discussions on the socially relevant issues in general. The lack of association between which opinion people have and their level of education is likely to indicate the marginal role of explaining the importance of RES in education.
\end{abstract}

\section{Introduction}

Nowadays, when the threats to climate change are becoming obvious, an increasing number of people worldwide are getting strongly favour clean energy sources over fossil fuels, and that belief transcends party lines and other viewpoints [1,2].

However, the public acceptance of the renewable energy sources (RES) might vary with the age, income, and, most notably, the level of education $[3,4]$. Up until now, education in

\footnotetext{
${ }^{*}$ Corresponding author: cabelkova@pef.czu.cz
} 
schools and universities has hardly been fully sustainable, meaning it has been reflecting such issues as sustainability and sustainable growth and development [5]. Thence, there is a pressing need for investing more resources into promoting sustainable education in order to change people's opinion related to the renewable energy sources [6,7].

In concrete terms, the aim of the sustainable education is to educate students (and the members of the general public) about the need for sustainable development by involving them in all aspects of teaching, research and services [8]. In practice, this means equipping them with the knowledge, skills, attitudes and values needed to build a sustainable future. It means reorienting the education system to help people think and act in a way that promotes a more sustainable planet. To this end, students should engage in authentic interdisciplinary learning activities, cultivate critical and creative thinking skills, and develop a value system that emphasizes responsibility for oneself and others and the planet, as well as respect for the environment and human rights. This is very crucial for forming the future economic and business culture in any country that would lead to the transparent business morale and fair practices which is often a problem $[9,10]$.

In this paper, we are aiming at testing the existence of links between the level of education and people's opinions of the renewable energy sources and other environmental initiatives. We assume that people form their opinions on the threats posed by the recent climate change and the necessity for moving away from fossil fuels to the renewable sources of energy such as solar, wind, hydro power or biomass based not only on their experience and the information spread by mass media but also based on their levels of education and experience. In order to verify our assumptions, we formulated the following research hypotheses:

1. The subjective opinion on possibility to replace the electricity generation from conventional sources (such as coal-fired or gas-fired power plants, nuclear power plants or large hydroelectric power plants) by generating electricity from wind, solar radiation and biomass combustion is related to the levels of education of the respondents.

2. The subjective opinion on how good the situation concerning the use of renewable energy sources is in the Czech Republic related to the levels of education of the respondents.

3. The existence of opinion on the on possibility to replace the electricity generation from conventional sources (such as coal-fired or gas-fired power plants, nuclear power plants or large hydroelectric power plants) by generating electricity from wind, solar radiation and biomass combustion is related to the levels of education of the respondents. Thence, the higher is the level of education, the more probable is that the respondent would have their own opinions on that matter.

4. The existence of opinion on how good the situation concerning the use of renewable energy sources is in the Czech Republic can be related to the level of education of the respondents. Thence, the higher the level of education, the more probable it might be that the respondent would have an opinion on that matter.

Overall, it is a whole system of research that combines current best practices in teaching and learning with content, core competencies and habits that require students to actively participate in shaping a sustainable future. In theory, education for sustainability withdraws from several teaching and learning methods and explicitly recognizes the role of students in shaping the future we want $[11,12]$. This is due to the fact that today's students will become the future leaders who will shape up the economic and social agenda including the corporate social responsibility $[13,14]$. Our research focuses on the relationship between education and sustainability. 


\section{Materials and methods}

The data used in this research were collected by the Czech Institute of Sociology in a representative survey conducted during May 2019 in the Czech Republic. A total of 1026 respondents (aged 15-95 years, $\mathrm{M} \pm \mathrm{SD}$ : $47.64 \pm 17.44$; $48.80 \%$ women) completed the questionnaire voluntarily and anonymously under the supervision of 217 experienced interviewers.

The case study of the Czech Republic was chosen due to its social and economic specifics (that is often reflected in its business sector and SMEs) and data availability [15]. The Czech Republic is a small open economy and a member of the European Union since 2004.

The educational distribution of the respondents presented $13,4 \%$ of primary education, $33,6 \%$ with secondary education without sampling with quotes (geographical location, age, gender and education) was employed to guarantee the representativity of the sample. According to this characteristic, the data sample is representative for the Czech Republic. The data used in this research were kindly provided by the Czech Social Science Data Archive and are deposited freely and can be used for academic and non-commercial purposes [16].

When it comes to the measures of opinions on renewable sources of energy, the main discussion on renewable on political debate concern the possibility of replacement of the traditional energy sources with renewables to reduce environmental damage and enhance sustainability of energy sector [17, 18]. The ability, willingness and the actual results in European Union (EU) countries differ significantly. Therefore, the indicators of public opinions on renewables concern: 1) the possibility to fully replace the sources of electricity by renewables; and 2) the subjective evaluation of the current situation with renewables in a country $[19,20]$.

Table 1.Comparative analysis of centralized and individual heat supply systems

\begin{tabular}{|l|r|c|c|c|c|}
\hline & $1, \%$ & $2, \%$ & $3, \%$ & $4, \%$ & No opinion, \% \\
\hline $\begin{array}{l}\text { It is possible to replace electricity from } \\
\text { conventional sources with renewables, 1 - yes, 4 } \\
\text { - no }\end{array}$ & 11,2 & 33,8 & 29,8 & 11,3 & 13,8 \\
\hline $\begin{array}{l}\text { Use of renewable energy resources in CR, 1 - } \\
\text { very good, 4 - very bad }\end{array}$ & 1,8 & 29,2 & 39,6 & 12,5 & 16,8 \\
\hline
\end{tabular}

The exact wording of the questions is presented below. The distributions of the respondents are presented in Table 1 that follows: "Do you think it is possible to replace electricity generation from conventional sources (such as coal-fired or gas-fired power plants, nuclear power plants or large hydroelectric power plants) by generating electricity from wind, solar radiation and biomass combustion?" (1- it is definitely possible to replace it, 2- it is rather possible to replace it, 3 - it is rather not possible to replace it, 4 - it is definitely not possible to replace it). "What do you think is the situation in our country concerning the use of renewable energy sources?" (1- very good, 2- rather good, 3 - rather bad, 4 - very bad).

From Table 1 above it follows that the respondents were split into two approximately equal groups: $45 \%$ of the respondents believe that it is or rather is possible to replace electricity from conventional sources with renewables while similar $41 \%$ believes that it is not possible.

The opinion of the respondent on the use of renewables in the Czech Republic was rather negative - more than a half of the respondents (52\%) believe that the situation in the Czech Republic (when it comes to using the renewable energy sources rather than traditional energy sources represented by the fossil fuels, such as coal and oil) is rather bad 
or very bad. Only one third of respondents $(31 \%)$ evaluate the situation positively or rather positively. Approximately $17 \%$ of the respondents did not reveal their opinion on this pressing matter preferring to opt out.

The distribution of the respondents on opinions about renewables with respect to education. Table 2 that follows below, presents the distribution of the respondents on opinion variables with respect to education.

Table 2. Indicators of attitude to renewable energy sources versus education, distribution of the respondents (in \%)

\begin{tabular}{|c|c|c|c|c|c|}
\hline & $1, \%$ & $2, \%$ & $3, \%$ & $4, \%$ & No opinion, $\%$ \\
\hline \multicolumn{6}{|l|}{ Higher Education } \\
\hline $\begin{array}{l}\text { It is possible to replace electricity from } \\
\text { conventional sources with renewables, } 1 \text { - } \\
\text { yes, } 4 \text { - no }\end{array}$ & 16,4 & 27,0 & 32,8 & 16,4 & 7,4 \\
\hline $\begin{array}{l}\text { Use of renewable energy resources in CR, } \\
1 \text { - very good, } 4 \text { - very bad }\end{array}$ & 1,1 & 31,7 & 39,7 & 16,9 & 10,6 \\
\hline \multicolumn{6}{|l|}{ Secondary education with state exam } \\
\hline $\begin{array}{l}\text { It is possible to replace electricity from } \\
\text { conventional sources with renewables, } 1 \text { - } \\
\text { yes, } 4 \text { - no }\end{array}$ & 10,5 & 38,0 & 30,6 & 9,3 & 11,6 \\
\hline $\begin{array}{l}\text { Use of renewable energy resources in CR, } \\
1 \text { - very good, } 4 \text { - very bad }\end{array}$ & 1,7 & 28,9 & 42,8 & 13,3 & 13,0 \\
\hline \multicolumn{6}{|l|}{ Secondary education without state exam } \\
\hline $\begin{array}{l}\text { It is possible to replace electricity from } \\
\text { conventional sources with renewables, } 1 \text { - } \\
\text { yes, } 4 \text {-no }\end{array}$ & 11,4 & 34,7 & 27,7 & 12,2 & 14,0 \\
\hline $\begin{array}{l}\text { Use of renewable energy resources in CR, } \\
1 \text { - very good, } 4 \text { - very bad }\end{array}$ & 2,9 & 28,9 & 37,0 & 11,4 & 19,5 \\
\hline \multicolumn{6}{|l|}{ Primary education } \\
\hline $\begin{array}{l}\text { It is possible to replace electricity from } \\
\text { conventional sources with renewables, } 1 \text { - } \\
\text { yes, } 4 \text { - no }\end{array}$ & 5,8 & 30,7 & 28,5 & 6,6 & 28,5 \\
\hline $\begin{array}{l}\text { Use of renewable energy resources in CR, } \\
1 \text { - very good, } 4 \text { - very bad }\end{array}$ & 0 & 28,5 & 37,2 & 7,3 & 27,0 \\
\hline
\end{tabular}

As it follows from Table 2 above, the proportion of the respondents with no opinion increases with decreasing education in both of the variables which are the possibility to replace of conventional sources with renewables and the use of renewable energy resources. In the group with primary education almost one third of the respondents do not have an opinion. Thence, it appears that any opinion on the sustainable future in general and the renewable energy that would replace the traditional fossil fuels might be channelled through educational processes and techniques that makes them crucial in the process of achieving sustainable development and mitigating the climate change.

For a much easier overview of the differences in the opinions of the respondents that have one, the following Figures 1 and 2 that follow below, display the relevant distributions. 


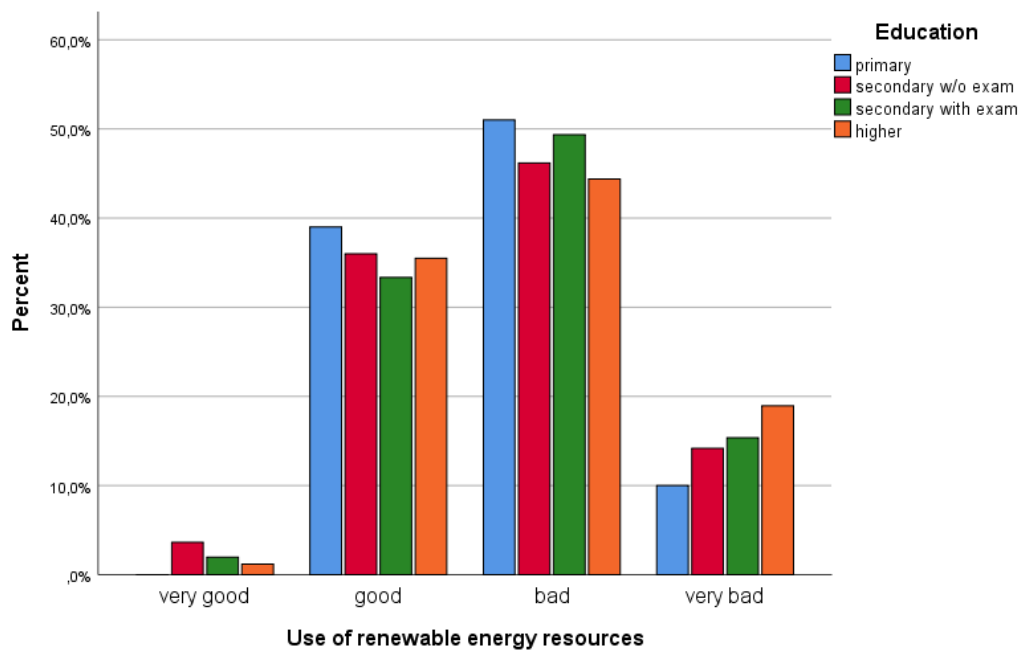

Fig. 1. Use of the renewable energy sources vs education, distribution of the respondents (in \%)

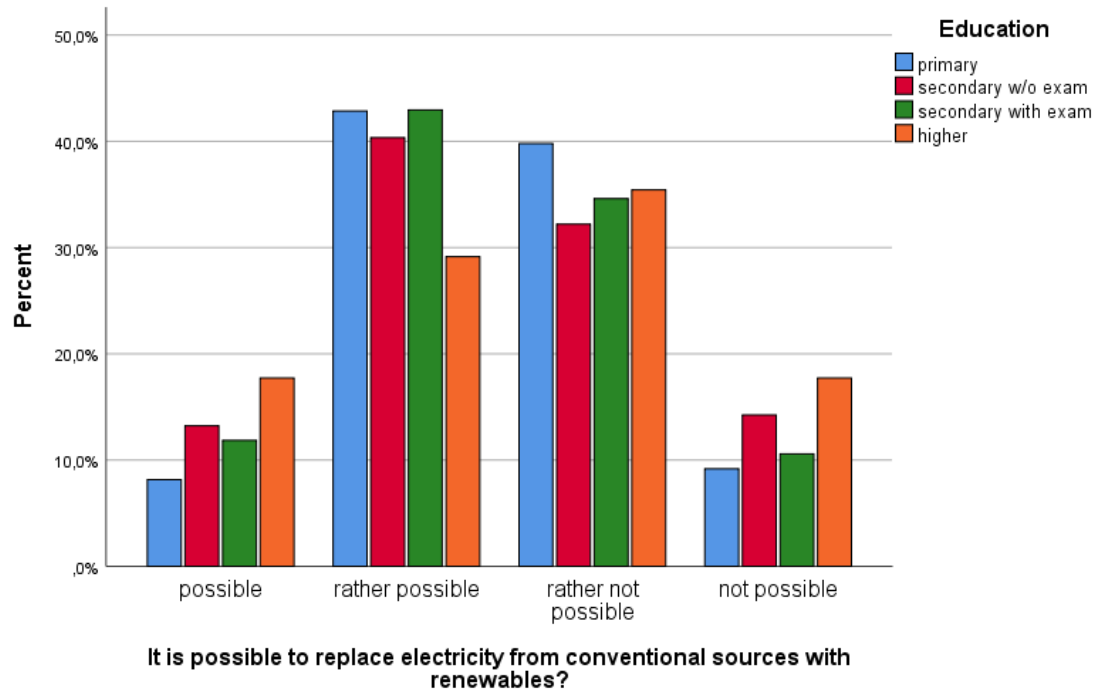

Fig. 2. Possibility to replace the electricity from the conventional sources with renewables vs. education, distribution of the respondents (in \%)

From the Table 2 and Figures 1 and 2 it becomes clear that the differences in distributions of the respondents with respect to education on use of renewable energy sources and possibility to replace electricity from conventional sources with renewables do not seem to be significant. There seem to be slight relation in category use of energy resources (very bad), where the proportion of the respondents increase with education.

Similarly, the percentage of the respondents in the category very good seem to decrease with education. However, more rigorous analysis might be needed. The deeper and more elaborate analysis in presented in the following sections.

\section{Empirical model}

In order to study the differences between groups of the respondent that differ in education one factor ANOVA was used. This method allows to compare the mean values in 
subjective possibility to replace electricity produced from conventional sources with renewables and in the use of renewables in the Czech Republic with respect to the levels of education of the respondents [21, 22]. If significant, the post-hoc tests are used for pairwise comparisons.

Given that significant part of the respondents did not have an opinion on renewables, one factor ANOVAS are also used to test the relation between education and existence of opinions on renewables.

Pearson and Spearman correlation were also used to test the possible linear relation between education and the opinions on renewables. The methodological rationale for reporting both Pearson and Spearman correlations in twofold: given the data are ordinal we are likely to violate normality condition and Spearman correlations should be used. However, because of the large number of observations and the law of big numbers, normality condition may be satisfied, therefore the Pearson correlation coefficient is also reported.

\section{Results and discussions}

In this section, the results of the empirical model that was briefly explained above are presented and explained. All in all, it appears that our hypotheses 1 and 2 about the relation between the opinion on renewables in the Czech Republic (good-bad) and the possibility to replace the electricity produced from traditional sources with renewables on one side and education of the respondents on the other side were not confirmed. It seems, that the groups of the respondents selected according to education do not differ in their opinion.

Moreover, there are significant relations between the existence of opinion on the variables above and education. The proportion of the respondents with no opinion increases with decreasing education in both of the variables. It means that the possibility to replace of conventional sources with renewables and the use of renewable energy resources. Thus, the hypotheses 3 and 4 are confirmed. In the group with primary education almost one third of the respondents does not have an opinion on both of the questions.

The last association may be caused by the increasing interest in renewables of people with higher levels of education as they are likely to be more open to all the discussions socially relevant issues in general. The lack of association between which opinion they have and education is likely to indicate low if any attention to these issues in the educative process on all the levels.

When it comes to people's opinion on RES and education, the ANOVAs and Spearman correlations can be shown as follows. The following figures (Figures 3 and 4) present the visualization of the differences in opinions with respect to education by mean values and $95 \%$ confidence intervals.

The relevant statistics for the association presented in graph 3 (the subjective possibility to replace electricity from conventional sources with renewables vs. education.) read as follows: ANOVA Sig. $=0,725$; Pearson corr. $=0,024$, Sig $=0,472$; Spearman rho $=0,17$, Sig. $=0,621 ; \mathrm{N}=880$. 


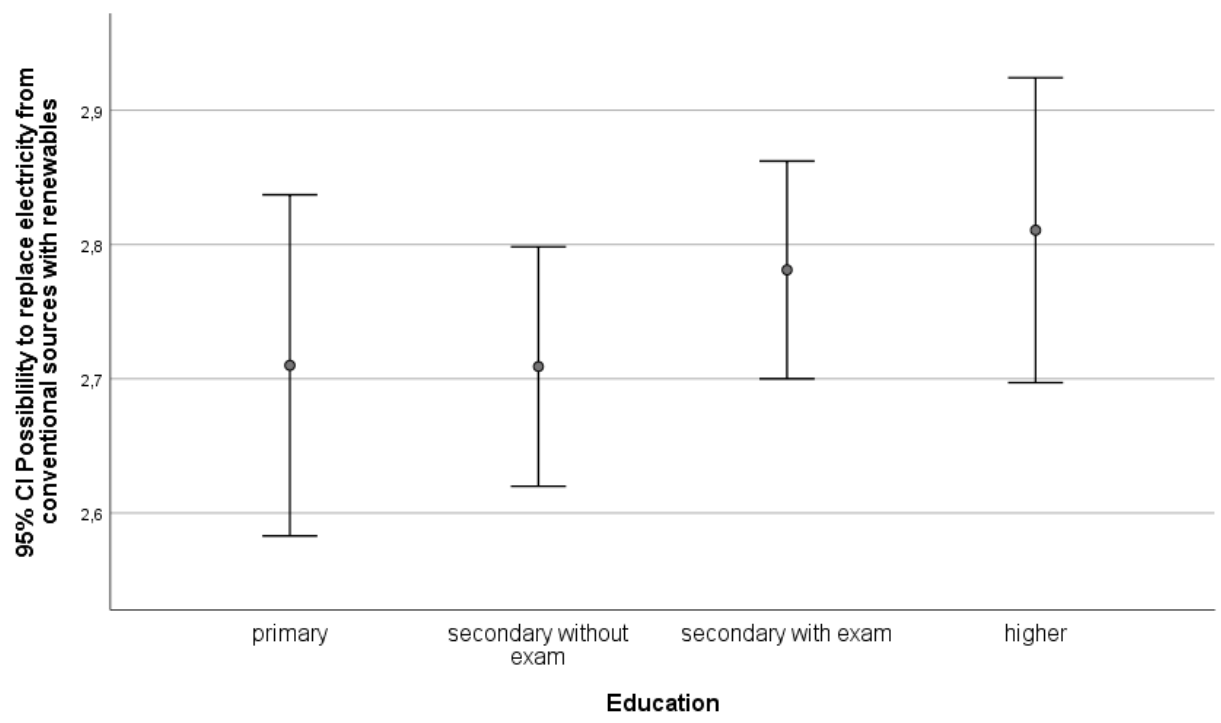

Fig. 3. Means and $95 \%$ confidence intervals for the subjective possibility to replace electricity from conventional sources with renewables vs. education.

All the significance levels were above 0,05. Thus, we do not find the support for the hypothesis 1.The following graph (4) and statistics present the comprehensive results for the hypothesis 2 .

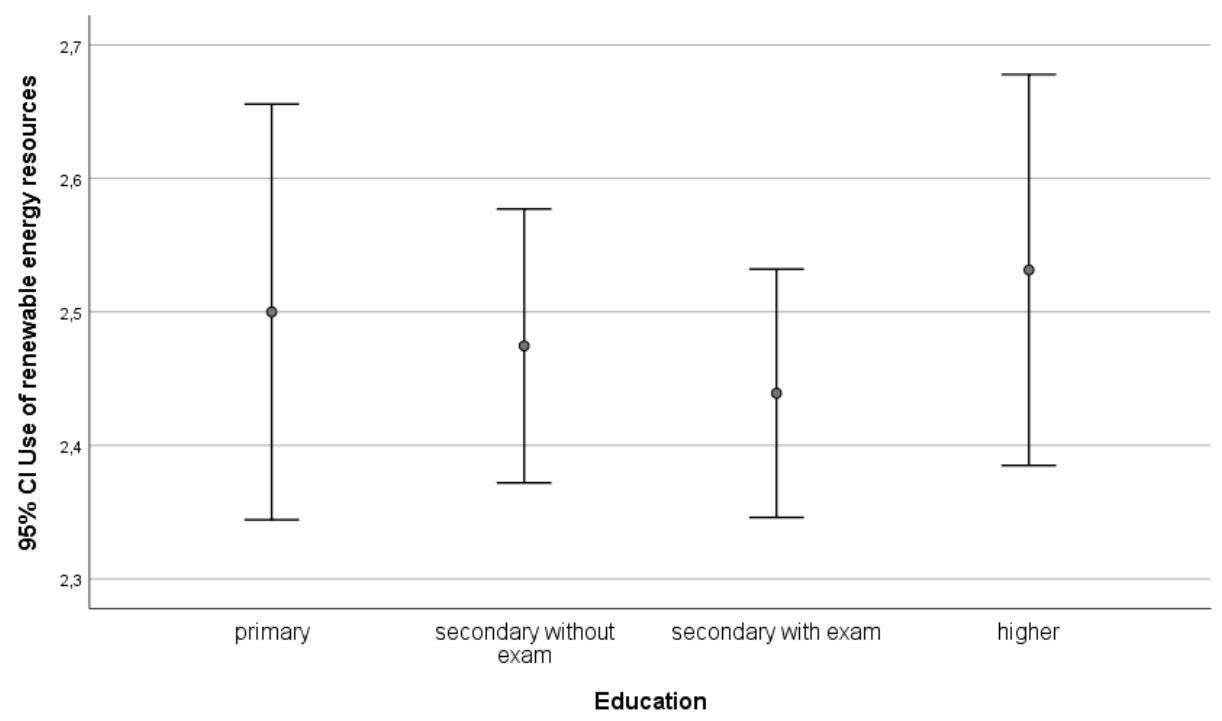

Fig. 4. Means and $95 \%$ confidence intervals for the opinion on use of renewable energy resources in CR vs. education

Here is the overview of the statistics: ANOVA sig. $=0,414$. Pearson corr. $=0,048$, Sig. $=0,162$; Spearman rho. $=0,043$, Sig. $=0,211 ; \mathrm{N}=850$.

From Figures 3 and 4 it follows that the confidence intervals for means intersect in all the cases, so, significant differences in mean values are not expected. More rigorous ANOVA analyses indeed do not support the hypotheses on the relation between education and the opinions on renewables studies above as significance level were well above the cup 
point of 0,05 . Because of this, Post-Hoc tests were not performed. Thus, the hypotheses 1 and 2 were not confirmed.

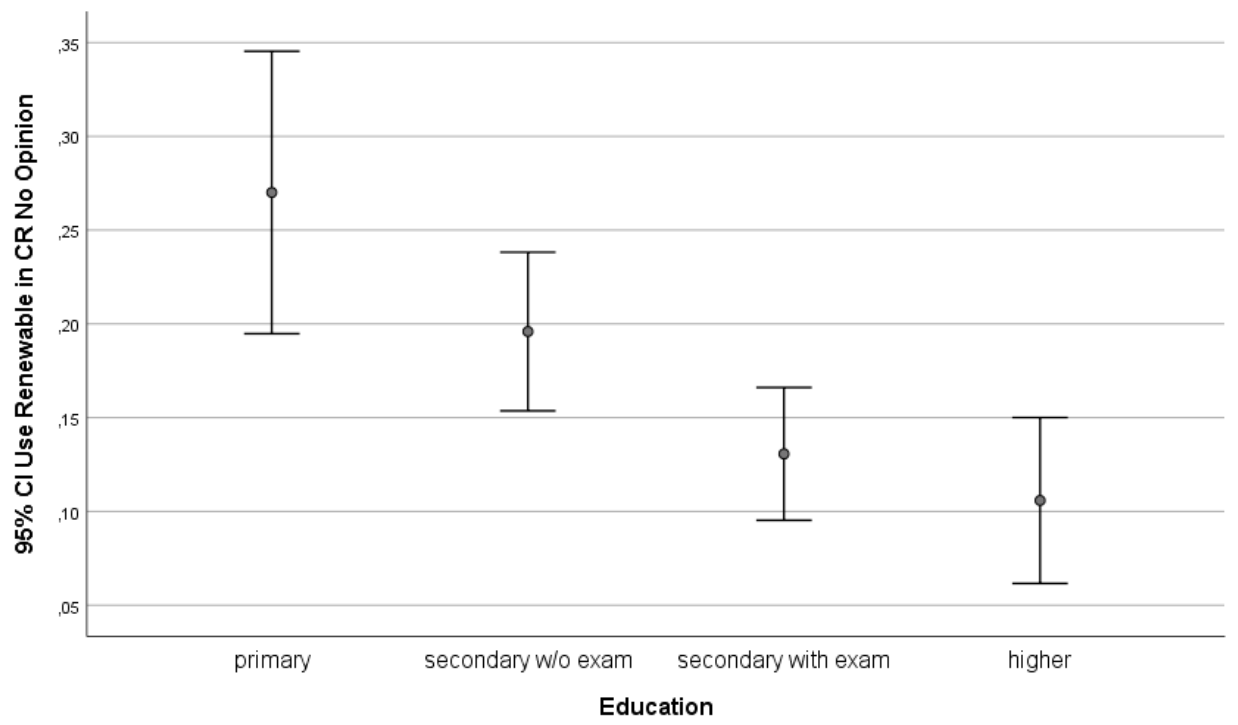

Fig. 5. Means and $95 \%$ confidence intervals for the existence of opinion on use of renewable energy resources in $\mathrm{CR}$ vs. education

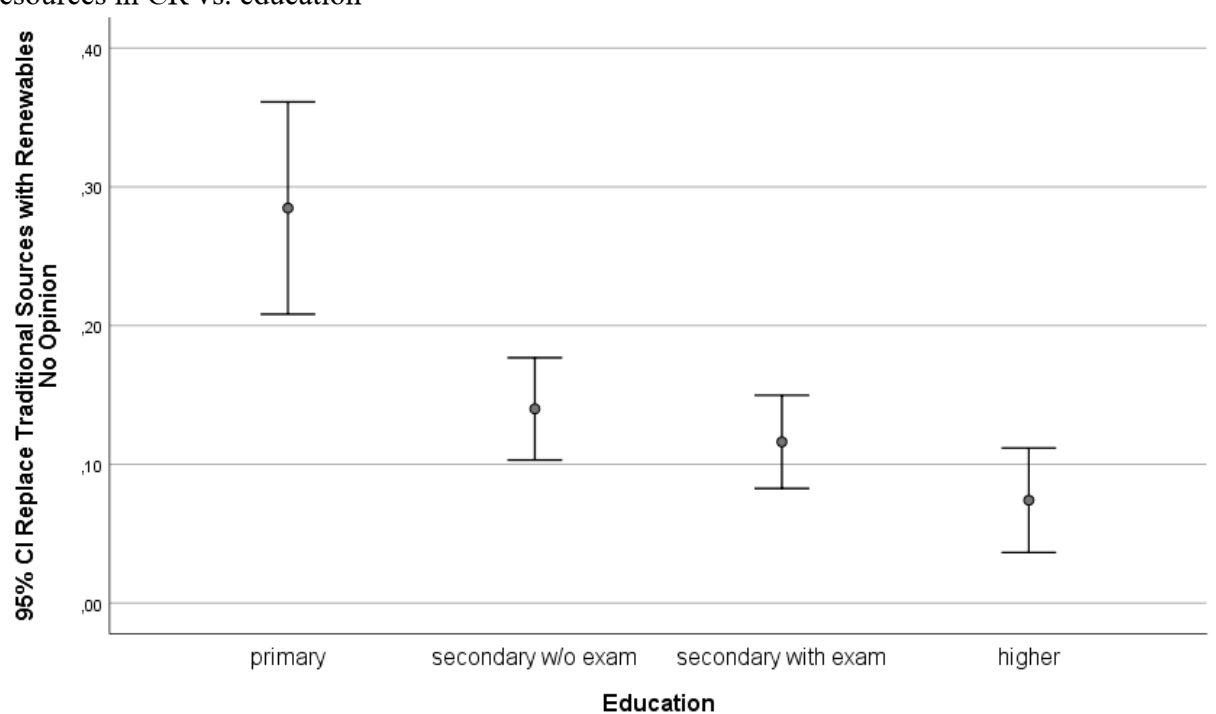

Fig. 6. Means and $95 \%$ confidence intervals for the existence of opinion on the possibility to replace electricity from conventional sources with renewables vs. education

Similarly, Pearson and Spearman correlation coefficients were not statistically significant. Thence, we do not have enough evidence to support the hypotheses 1 and 2 about the relations between the opinion variables and education.

Regarding the existence of opinion vs. education, Figures 5 and 6 present the means and $95 \%$ confidence intervals for the relations between the existence of opinion on renewable variables and the level of education of the respondents.

Hence, the significant linear associations between the existence of opinion ( 1 meant no opinion, 0 - opinion exist) and education are highly visible from the graphs 6 a 7 . This 
relation was also supported by the correlation analyses, where Spearman correlation coefficient for education and the existence of opinion on renewables in the Czech Republic was equal to $-0,117$ (Sig. $=0,000$, Spearman Rho $=-0,127$, Sig. 0,000$)$ and for existence of opinion on the possibility to replace the electricity produced from traditional sources with renewables was equal to $-0,147$ (Sig. $=0,000$, Spearman rho $=-0,157$, Sig. 0,000).

The negative sign of the coefficient was caused by the inverse coding of the opinion existence variable (1 meant no opinion). Thus, we can conclude that the higher is the level of the obtained education, the more probable it might happen that the respondent would have some personal and articulated opinion on the renewable energy sources in the Czech Republic and on the possibility to replace the traditional (fossil) sources of energy with the electricity generated with the help of renewables. Our hypotheses 3 and 4 were therefore confirmed and supported by the empirical evidence.

\section{Conclusions}

Overall, our paper examined the opinion people have on renewable energy sources and sustainable development and their level of education. Our results showed that the level of education hardly contributes to having a higher environmental awareness and the willingness to accept RES as the new and more ecological source of electric energy.

These results are quote surprising but hardly unexpected. Sustainable education is a goal that needs to be developed systematically and to work on consistently. If information on sustainable development remains sporadic and marginal, people are not likely to change their attitudes towards such issues as global climate change or the global warming. It is necessary to keep inform them on the threats and dangers traditional fossil fuels represent and the new environmentally-friendly renewable energy sources offer all through their educational paths, starting from the primary school, going all the way through college and then to the higher educational establishments.

Sustainable education is intended to improve and expand students' ability to identify and promote inclusive and sustainable solutions through their creative processes. As the work of the Sustainable Development Goals (SDG) in transforming sustainable development and learning culture and improving the living conditions of people with their local and objective context shows, they are at the heart of our design methods. Recognition, action and accountability that create a context in which higher education can be reinvented as a platform for the development of sustainable learning and building a sustainable society.

At the same time, sustainable education should aim at fostering the recognition of risk and resilience, and encouraging people to take action to promote prosperity - addressing issues of accountability and social responsibility. With regard to the above, higher education institutions play a crucial role in implementing and promoting sustainable development initiatives. One of the most important questions to be answered is what university leaders, lecturers and students can do to implement sustainable developments in their institutions. To reduce the barriers to academic success, fairness is part of understanding students learning needs. With the increasing demands on society and the environment due to increasing urbanization, migration and human migration, it is clear that global action is needed to build a more sustainable future. Building a sustainable future means more than just creating green campuses and implementing recycling efforts and initiatives for global civic engagement.

Given its role in the global economy and its importance for the future of our planet, higher education can serve as a powerful means of building a more sustainable future. As the world becomes increasingly globalised and interdependent, it is becoming more important for creating a sustainable future. In recent years, the concept of education and sustainable development has become a central educational initiative, helping to address 
many of the problems associated with human development. High on this list of priorities should be the development of sustainable education, especially in the context of environmental education. But it is also crucial to integrate sustainable development into the context of education. Education is an important part of society's ability to face and address the challenges of sustainable development. It can be the basis for teaching people to respect the needs of the environment, but that is not the whole answer to the problem. People around the world need to be educated about how to improve the quality of life without creating problems for the future or unfairly affecting other people's lives.

Climate change, resource scarcity and the workforce are issues that are not resolved in the short term, but are crucial for a company's long-term growth. We need to proactively ensure that our current and future business students understand the importance of sustainability for future business success. Today's students will soon have to face complex sustainability challenges that require developing entirely new skills and attitudes. Building on case studies from all around the world, scientists and practitioners have provided insight into the demands of our education system in the face of rapid ecological and societal change. This is the first time that economic organisations and scientists have joined forces to address environmental or social issues. In all sectors, companies are committed to finding solutions to the challenges the world is currently facing, such as climate change, resource scarcity and environmental degradation. Crucially, there is no doubt that environmental disasters are on the increase, not only in the United States, but also in Europe, Asia, Africa and Latin America. Fortunately, educators of all disciplines have existing strengths that contribute to as a strength model. Talented educators have already taught some of these and are expanding them to include other concepts of sustainable development. One of the effective ways to promote this is through a reflexive world view that evolves constantly with the factors that determine how the world works. With this approach, the synergistic strengths of combined training disciplines can convey the knowledge, problems, skills, perceptions and values. However, using this strength model requires to pull all the pieces together and develop an understanding of the role that individuals, communities, and nations must play in a sustainable world.

Our results might be of a special value for educators worldwide. In addition, they might be relevant for stakeholders and policy-makers intending to find their target audiences for supporting sustainable development and fostering the climate protection.

\section{References}

1. B.B. Uzoejinwa, X. He, S Wang, A.E.F. Abomohra, Y Hu, Q Wang, Energy conversion and management, 163, 468 (2018)

2. M. Fairbrother, I.J. Sevä, J. Kulin, Global Environmental Change, 59, 102003 (2019)

3. V. Bertsch, M. Hall, C. Weinhardt, W. Fichtner, Energy, 114, 465 (2016)

4. P. Roddis, S. Carver, M. Dallimer, G. Ziv, Energy Research \& Social Science, 56, $101226(2019)$

5. B. Crespo, C. Míguez-Álvarez, M.E. Arce, M. Cuevas, J.L. Míguez, Sustainability, $\mathbf{9 ( 8 ) , ~} 135$ (2017)

6. L.C. Hamilton, J. Hartter, E. Bell, PloSONE, 14(7), e0217608. (2019)

7. S. Balitskiy, Y. Bilan, W. Strielkowski, Journal of Security \& Sustainability Issues, 4(2), 125 (2014)

8. V. Campos-Guzmán, M.S. García-Cáscales, N. Espinosa, A. Urbina, Renewable and Sustainable Energy Reviews, 104, 343 (2019)

9. I. Cabelkova, W. Strielkowski, M. Mirvald, Transformations in Business \&Economics, 14(1), 65 (2015) 
10. P. Koudelková, W. Strielkowski, D. Hejlová, Danube: Law, Economics and Social Issues Review, 6(1), 25 (2015)

11. C.D. Trott, A.E. Weinberg, Sustainability, 12(16), 6400 (2020)

12. B. Sundberg, S. Areljung, C. Ottander, NorDiNa: Nordic Studies in Science Education, 15(4), 358 (2019)

13. J. Lu, L. Ren, J. Qiao, S.Yao, W. Strielkowski, J. Streimikis, Sustainability, 11(15), $4128(2019)$

14. J. Gessner, D. Bortree, Journal of Public Relations Education, 5(2), 167 (2019)

15. J. Abrham, W. Strielkowski, M. Vošta, J. Šlajs, Agricultural Economics, 61(10), 450 (2015)

16. Sociologický ústavAkademie věd ČR (2019). Center for Public Opinion Research. Our Society 2019, doi: 10.14473/V1905, http://nesstar.soc.cas.cz

17. P. A. Owusu, S.Asumadu-Sarkodie, Cogent Engineering, 3(1), 1167990 (2016)

18. M.J. Burke, J.C. Stephens, Energy Research \& Social Science, 35, 78 (2018)

19. I. Čábelková, W. Strielkowski, I. Firsova, M. Korovushkina, Energies, 13(7), 1742 (2020)

20. C. Herbes, B. Rilling, S. MacDonald, N. Boutin, S. Bigerna, Energy Policy, 141, 111473 (2020)

21. E. Bozorgparvar, M. Yazdanpanah, M. Forouzani, B. Khosravipour, Journal of Cleaner Production, 203, 769 (2018)

22. A.D. Stewart, M. Gardiner, J. MacDonald, H. Williams, Applied Ergonomics, 90, 103247 (2020) 